\title{
O PET geografia da UFRN e a sua contribuição na formação profissional
}

UFRN PET geography and its contribution in vocational training

\author{
Alessandro Dozena \\ Antonia Rosimeire Pinheiro Maia \\ Breno de Lima Garcia Medeiros \\ Dara Emanuella Rodrigues de Freitas Cruz \\ Daniel Carlos Alves Santos \\ Felipe Silveira Félix \\ Jéssica Alves dos Santos \\ Jucielma Fonseca do Nascimento \\ Larícia Gomes Soares \\ Luana de Holanda Viana Barros \\ Lucas Bezerra Maciel \\ Marcellus Silva Arruda Miranda \\ Nilvan Alves Fernandes \\ Vinícius Mendes dos Santos*
}

\section{RESUMO}

O Programa de Educação Tutorial (PET) passou por vários momentos até ser implementado nas universidades federais, sendo que algumas de suas propostas visam auxiliar e incentivar os docentes e discentes dos cursos de graduação através de projetos de pesquisas, ensino, extensão, e trabalhos realizados em grupos. Aos bolsistas selecionados pelo programa é permitido que permaneçam até concluírem os seus respectivos cursos de graduação. Nesse contexto, o presente artigo avalia a contribuição do PET na formação profissional dos bolsistas que participaram do programa no curso de Geografia da UFRN na modalidade bacharelado e licenciatura, entre os anos de 2004 e 2018. A metodologia da pesquisa que resultou nesse artigo consistiu em reuniões com o grupo PET Geografia, em pesquisas bibliográficas para elucidar as diretrizes do programa e o seu contexto histórico de formação, e a aplicação de um questionário online com o intuito de coletar dados sobre a contribuição que do PET Geografia da UFRN na formação dos graduados que passaram pelo programa. Desse modo, foi criado um roteiro com perguntas e respostas para que os expetianos respondessem, evidenciando o laço que alguns ainda possuem com o programa em diferentes gerações. Evidenciou-se que o Programa de Educação Tutorial em Geografia da UFR tem contribuído para a formação de profissionais e docentes qualificados, e cumprido os seus objetivos.

PALAVRAS-CHAVE: Programa de Educação Tutorial, Geografia, Pesquisa.

\section{ABSTRACT}

The Program of Tutorial Education (PET) went through several moments until it was implemented in the federal universities, and some of its proposals are aimed at helping and encouraging undergraduate teachers and students through research projects, teaching, extension, and accomplished work in groups. Scholarship holders selected by the program are allowed to remain until they complete their respective undergraduate courses. In this context, the present article evaluates the contribution of the PET in the professional training of the

* Universidade Federal do Rio Grande do Norte; petgeografiaufrn@gmail.com 
scholarship holders who participated in the program in the Geography course of UFRN in the baccalaureate and licenciatura modality, between the years of 2004 and 2018. The methodology of the research that resulted in this article consisted of meetings with the PET Geography group, in bibliographic research to elucidate the guidelines of the program and its historical context of formation, and the application of an online questionnaire with the intention of collecting data on the contribution of PET Geography of UFRN in the training of graduates who went through the program. In this way, a script was created with questions and answers so that the ex-students responded, evidencing the bond that some still have with the program in different generations. It was evidenced that the Geography Program of Tutorial Education of the UFRN has contributed to the formation of qualified professionals and teachers, and fulfilled its objectives.

KEYWORDS: Tutorial Education Program, Geography, Research.

\section{INTRODUÇÃO}

O Programa Especial de Treinamento PET foi criado em 1979 pela Coordenação de Aperfeiçoamento de Pessoal de Nível Superior - CAPES, e posteriormente, no final de 1999, teve sua gestão deslocada para a Secretaria de Educação Superior do Ministério da Educação - SESU/MEC. Em 2004 teve o seu nome modificado para Programa de Educação Tutorial. Segundo Martins (2007), o contexto de sua criação foi o de um conjunto de atividades que buscavam fortalecer o ensino superior no Brasil. Desde o período em que ficou sob a gestão da CAPES, até meados de 2004, já com a SESU/MEC, especificadamente sob a responsabilidade do Departamento de Modernização e Programas da Educação Superior DEPEM, o PET já apresentava uma importância e um potencial de qualificação de seus bolsistas, e por isso já merecia ser expandido e aprimorado. A partir desse momento, entrou em vigor a etapa conhecida como "Fase de Institucionalização", sendo que:

No contexto de retomada e de dinamização do PET no âmbito do Ministério da Educação, destacam-se a Lei $n^{\circ} 11.180$ e a Portaria $n^{\circ} 3.385$, ambas de setembro de 2005. Estes instrumentos normativos imprimiram um novo formato ao programa ao tempo em que lhe deram um caráter institucional (MARTINS, 2007, p.01).

O PET passou a apresentar um maior vínculo acadêmico-administrativo com as Instituições de Ensino Superior (IES), a partir do apoio promovido pelas Pró-Reitorias de Graduação. Com isso, o Programa começou a ganhar os moldes atuais com a configuração de 12 alunos por grupo e um tutor, todos recebendo mensalmente uma bolsa. O Programa também ganhou bases filosóficas bem definidas que estão pautadas na tríade ensino, pesquisa e extensão. Essas características fazem do PET um programa de destaque no meio acadêmico, 
acentuando a formação de profissionais capacitados para várias situações, conforme explicitam Xavier e Goulart (2008):

\begin{abstract}
A proposta trazida pelo PET a comunidade universitária estabelece um divisor importante entre ele e qualquer outro programa de formação acadêmica: a ideia de enfatizar o ensino, a pesquisa e extensão, pilares básicos que sustentam o saber universitário, consubstanciada pelo aspecto político adquirido ao longo dos anos pelo programa e pela ideia de tutoria de pequenos grupos por docentes capacitados para a função, definem os ingredientes básicos necessários para a formação de líderes (XAVIER;GOULART, 2008, p.1).
\end{abstract}

Entre as capacidades desenvolvidas por um petiano está a capacidade de liderança, a resolução de problemas e o trabalho em grupo, entre outras habilidades que o programa proporciona. Prova disso é o caso de ex-petianos que posteriormente se tornaram tutores do programa. Na atualidade, segundo o Ministério da Educação, há no Brasil um total de 842 grupos PET, distribuídos nas 121 IES do país. Uma dessas instituições é a Universidade Federal do Rio Grande do Norte (UFRN), que conta com um total de 18 grupos PET divididos em PET SESU: Geografia, Filosofia, Química, Engenharia Elétrica, Engenharia Química, Estatística, Medicina, Ciência da Computação, Física, Ciências Sociais, Engenharia de Produção e Matemática; e os grupos PET Conexões: Água Viva, Direito à Cidade, Diversidade de Saberes e Lutas Populares, Comunidade Urbana Seridó e Comunidade do Campo.

Os grupos PET SESU foram os originalmente instituídos na UFRN, sendo que os primeiros grupos são da década de 1990, a exemplo do PET de Geografia, Química e Engenharia Química. Os últimos grupos institucionalizados na UFRN correspondem aos grupos Conexões de Saberes. Dessa forma, o PET na UFRN vem ao longo de vários anos desempenhando um papel fundamental na formação acadêmica dos discentes que tiveram a oportunidade de pertencer a comunidade petiana.

Pretendemos aqui relatar brevemente a longa história do PET Geografia na UFRN. A implementação desse programa no Departamento de Geografia (DGE) se deu no dia 15 de setembro de 1996, sob a tutoria da professora Dr ${ }^{\mathrm{a}}$ Beatriz Maria Soares Pontes. Atualmente, o PET Geografia conta com 12 bolsistas efetivos e 1 bolsista voluntário, todos cadastrados no Sistema de Gestão do Programa de Educação Tutorial - (SIGPET).

Assim como a renovação contínua dos bolsistas no programa, há também a mudança periódica dos tutores. Dessa forma, em outubro de 2000, o professor Dr. Anelino Francisco da Silva assume a tutoria. No ano de 2006, o programa é assumido pelo professor Dr. Ademir 
Araújo da Costa, permanecendo como tutor até o ano de 2012. Neste mesmo ano, o professor Dr. Alessandro Dozena assume a frente do PETGEO, deixando-o em 2015. O professor Dr. Ademir Araújo da Costa volta a assumir o programa até o ano de 2017, e neste ano, o professor Alessandro Dozena retorna como tutor e permanece até o presente momento (2019). Seguindo a filosofia do programa, o PET Geografia desenvolve atividades que se enquadram na tríade universitária como: trilhas geográficas, mini-cursos, visitas técnicas, cafés geográficos, atividades de extensão em diferentes municípios, entre várias outras ações ${ }^{1}$.

Essas ações potencializam o desenvolvimento profissional e acadêmico dos discentes como abordaremos na sequência, quando analisaremos e avaliaremos as condições dos membros discentes que participaram do programa no Departamento de Geografia da UFRN desde a sua criação em 1996, evidenciando a contribuição do programa na formação dos mesmos. Nesse sentido, nossos objetivos específicos no artigo são:

- Realizar levantamentos quantitativos e qualitativos com a finalidade de investigar a atuação dos egressos enquanto profissionais;

- Avaliar quantitativamente o nível de satisfação dos membros egressos em relação a temáticas como a relação com os tutores e a relação com o grupo.

- Elaborar gráficos e tabelas indicando os resultados obtidos e evidenciando os seus resultados.

\section{O percurso dos egressos}

Para a organização do trabalho foram realizadas reuniões de planejamento e estruturação do artigo construído coletivamente. Inicialmente foram realizados levantamentos bibliográficos para a construção e contextualização da temática através de pesquisa documental nas fichas cadastrais, para a efetivação do levantamento histórico do público alvo dos questionários. Foi elaborado um questionário virtual em forma de entrevista a partir da ferramenta Google Docs e sendo destinado, aos ex-petianos do Programa de Educação Tutorial PET do Departamento de Geografia da UFRN. No total foram enviados 65 mensagens para o e-mail de ex-membros do programa de 2004 a 2018, tendo sido obtidas 19 respostas. A período escolhido resulta do fato de que a partir de 2004 o PET passou a ser chamado de Programa de Educação Tutorial. A partir das respostas dos questionários, os

\footnotetext{
${ }^{1}$ Tais ações podem ser consultadas em: http://petgeografiaufrn.blogspot.com/
} 
dados foram tabulados e foram gerados gráficos, tabelas e quadros com o auxílio do software Excel, bem como foram discutidos os resultados obtidos.

Sabe-se que o Programa de Educação Tutorial de Geografia da UFRN apresenta em sua essência orientações básicas para que tanto os petianos quanto o tutor possam ter um bom desempenho social, acadêmico e profissional durante a permanência no programa, e também posterior a ela. No tocante à relação social entre os membros do programa e destes com o tutor (a), o Manual de Orientações Básicas do PET (2006), nas primeiras cláusulas do Termo de Compromisso, apresenta como pontos a serem seguidos pelos membros discentes e tutores o respeito "a diversidade e pluralidade de ideias e opiniões dos demais membros dos grupos PET, da comunidade universitária e da comunidade em geral; além de buscar se manter a urbanidade e atitudes éticas".

Verifica-se que além de contribuir de forma positiva com o amadurecimento das relações interpessoais dos membros, o PETGEO ainda exige, de acordo com o Manual de Orientações Básicas (2006), a manutenção de um bom rendimento acadêmico na graduação (ser exemplo para os seus colegas de turma); e o satisfatório rendimento acadêmico avaliado pelo tutor, bem como por seus colegas de grupo. Dessa maneira, o programa incentiva o aluno a seguir "aprendendo a aprender" de forma mais efetiva, a qual refletirá em seus resultados e índices acadêmicos, pois ao fazer parte do programa o aluno terá a oportunidade de participar de eventos e atividades que envolvem a tríade universitária (ensino, pesquisa e extensão).

Dentro dessa perspectiva, o petiano poderá publicar ou apresentar trabalhos em eventos de natureza acadêmico-científica, promover minicursos e atividades de extensão, participar e organizar eventos, além da realização de pesquisas coletivas e individuais. Essas atribuições fazem com que o aluno se torne um ser ativo na construção de seu próprio conhecimento, em todos os âmbitos acadêmicos, encontrando formas de contribuir e retribuir para a sociedade esses ganhos. Sendo assim, as contribuições do Programa vão além da obtenção de melhores índices acadêmicos, já que a educação e o conhecimento têm o intuito de transcender o ambiente universitário, buscando-se preparar o aluno para a vida, e formando um cidadão mais consciente e crítico.

Dessa forma, temos o PET como colaborador e auxiliador da formação na trajetória acadêmica e cidadã de seus membros. Ademais, o programa igualmente contribui com o processo de independência e autonomia na execução de ações no ambiente profissional, as quais apresentaram retornos positivos na amostra de resultados obtidos em nossas análises. Diante do exposto, verifica-se o quanto o PET Geografia da UFRN, desde a sua criação em 1996, contribuiu para uma formação mais completa dos alunos de graduação em Geografia, 
no tocante a expansão da cidadania, e na formação de profissionais com alto grau de desempenho acadêmico e boa performance profissional em seus ambientes de trabalho.

No levantamento de dados realizado com membros egressos do PET Geografia da UFRN, notou-se um bom grau de satisfação na relação interpessoal entre os membros do Programa, assim como com o tutor. Dessa forma, evidencia-se o compromisso do grupo com os deveres enquanto grupo PET, como preservar e incentivar a urbanidade, além de respeitar a diversidade e pluralidade de ideias e opiniões.

Desse modo, dos dezenove egressos que participaram da pesquisa, apenas um (representando 5,3\% da amostra), mostrou-se pouco satisfeito, sendo a mesma pessoa a responder, mais adiante na pesquisa, que o programa pouco contribuiu para o seu desenvolvimento. Contudo, os demais participantes ressaltaram um bom nível de satisfação, entre "satisfeitos" - 08 egressos, "muito satisfeitos" - 06 egressos, "totalmente satisfeitos" 04 egressos, como pode ser observado no Gráfico 1.

Gráfico 1 - Nível de satisfação na relação entre os bolsistas do PET Geografia da UFRN

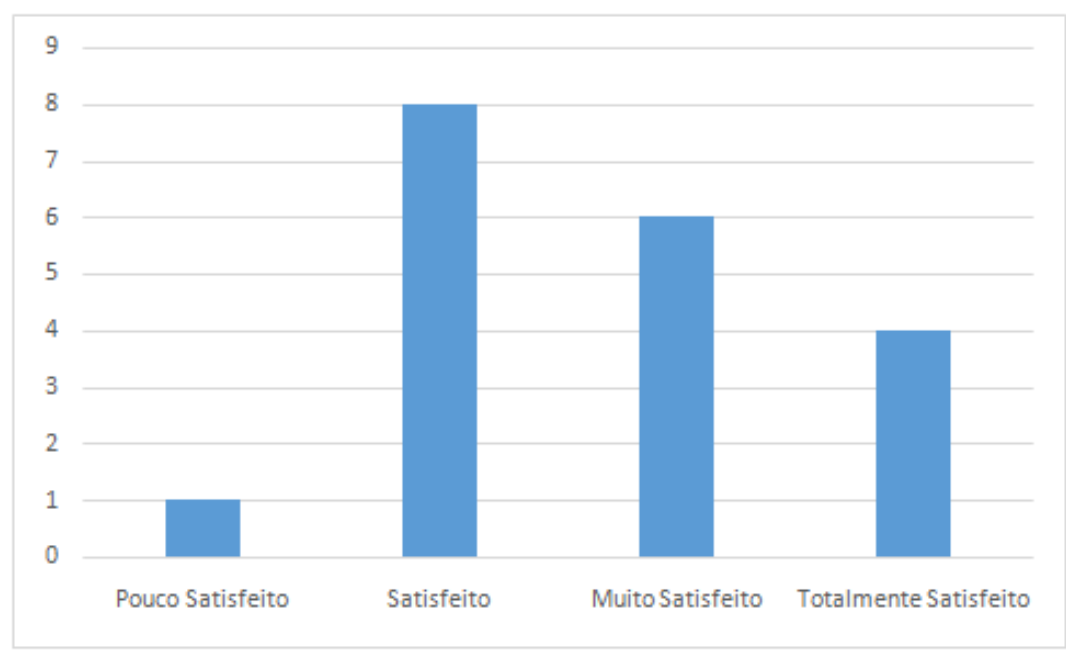

Fonte: Pesquisa própria / PET Geografia UFRN (2018).

No tocante a relação com o tutor, as análises evidenciaram um nível ainda maior de satisfação, com 05 participantes que se mostraram "satisfeitos", 08 - "muitos satisfeitos" e 06 - "totalmente satisfeitos" (Gráfico 2). É expresso, desta forma, o total êxito na relação de membros com o tutor do grupo, em diferentes tempos, tendo em vista que os participantes da pesquisa fizeram parte de diferentes gerações do grupo, convivendo com tutores distintos, entre eles o professor Dr. Ademir Araújo da Costa e o professor Dr. Alessandro Dozena.

Gráfico 2 - Nível de satisfação na relação dos bolsistas com o tutor do PET Geografia. 


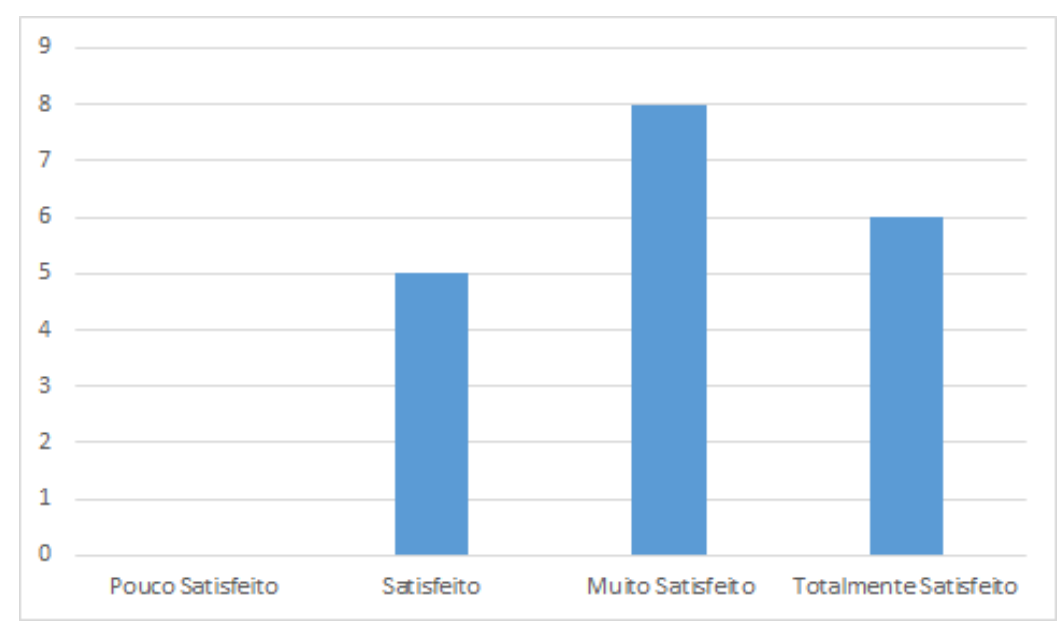

Fonte: Pesquisa própria / PET Geografia UFRN (2018).

Tomando como base a essência do Programa de Educação Tutorial, já mencionado anteriormente, obtivemos resultados positivos quando questionamos os participantes da pesquisa (Gráfico 3), evidenciando assim o quanto o programa contribuiu não apenas no processo de formação acadêmica dos seus membros, como também no que se refere a formação social e cidadã de seus bolsistas e voluntários. Evidencia-se assim, um crescente nível de satisfação dos seus participantes, observado no gráfico 3; e que estes extraíram do Programa o seu melhor, de acordo com o que estabelece o Manual de Orientações Básicas (2006):

Uma formação global, tanto para os membros quanto para os alunos da graduação ao qual o grupo está inserido, realizando entre ambos uma profusão de experiências enriquecedoras que contribuem para a formação cidadã e acadêmica (MOB/PET MEC, 2006).

Assim sendo, a prática metodológica da educação tutorial possibilita aos seus participantes o desenvolvimento de habilidades de análise crítica de suas ações, assim como resolução de problemas, independência e automação na execução de trabalhos e atividades.

Gráfico 3 - Nível de satisfação com o PET na sua essência 


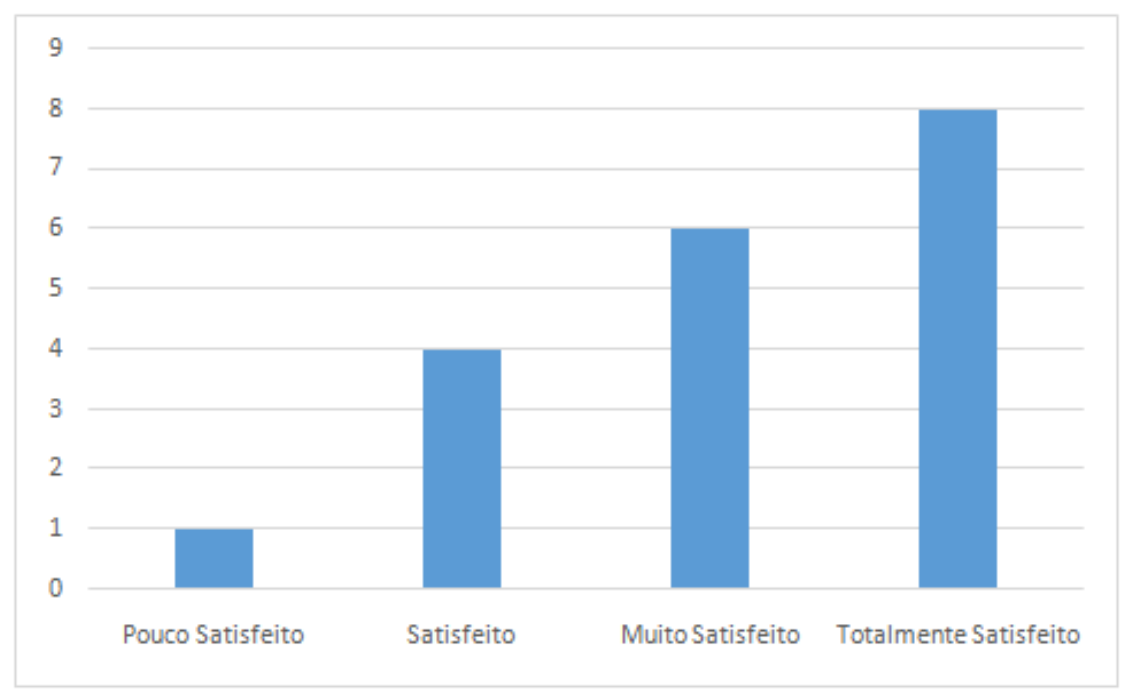

Fonte: Pesquisa própria / PET Geografia UFRN (2018).

Segundo a Portaria no 976/2010, o Programa de Educação Tutorial visa desenvolver algumas competências específicas, entre elas as que se fundamentam nos rendimentos acadêmicos, desenvolvendo práticas acadêmicas com padrões de qualidade e excelência, mediante grupos de aprendizagem tutorial de natureza coletiva e interdisciplinar. Essas práticas também contribuem para o aumento da qualidade da formação acadêmica de seus membros e dos alunos de graduação, além de contribuir para o fortalecimento e difusão da educação tutorial como prática de formação na graduação. Nesse sentido, o PET Geografia UFRN é visto como um incentivador no sentido de seus integrantes sentirem cada dia mais vontade de melhorar e superar seus limites, com o intuito de alcançar seus objetivos futuros. Dessa maneira, seguindo esses elementos, verificou-se o relato dos participantes acerca da contribuição a seus desempenhos acadêmicos, o que pode ser observado no Gráfico 4.

Gráfico 4 - Contribuição do PET Geografia no desempenho acadêmico do membro discente.

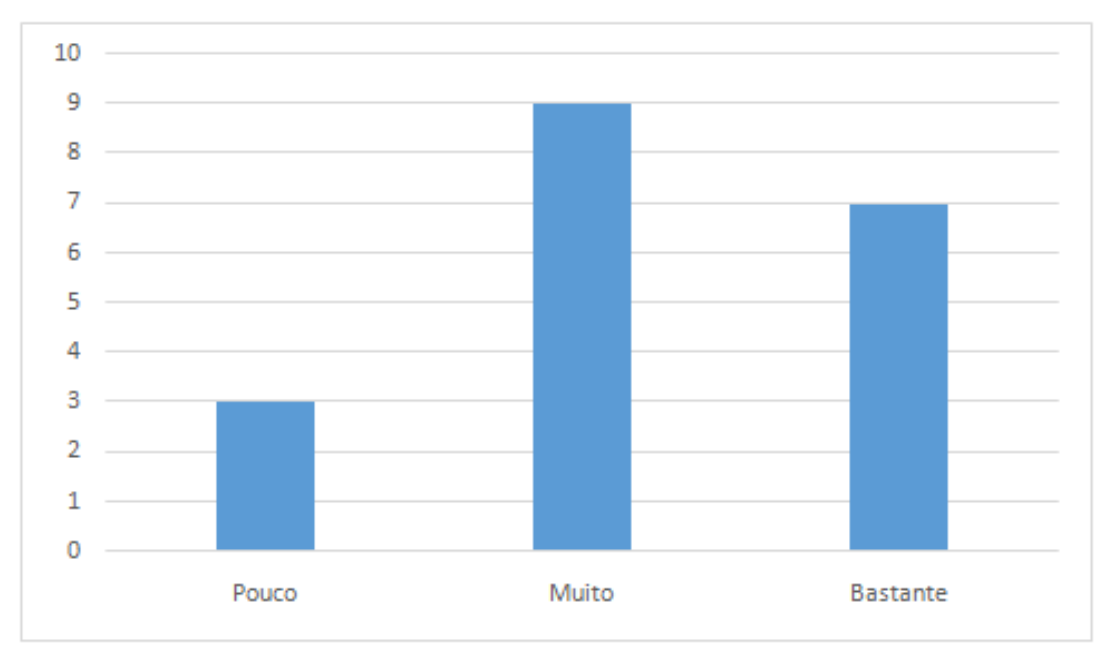

Fonte: Pesquisa própria / PET Geografia UFRN (2018).

OBSERVATORIUM: Revista Eletrônica de Geografia, v.10, n.1, p.88-100. jan/abr 2019 
Ainda de acordo com a portaria mencionada, em suas competências, temos depoimentos no tocante à maior qualificação na formação profissional, pois o PET possibilita uma formação mais completa. O programa procura preparar os membros para a vida acadêmica e para o mercado de trabalho, seja na área técnica da ciência geográfica (bacharelado), ou na preparação docente para o ensino básico ou superior. Em virtude disso, é válido ressaltar que o PET visa motivar "a formação de profissionais e docentes de elevada qualificação técnica, científica, tecnológica e acadêmica" (Manual de Orientações Básicas, 2006). Em complemento, procura incentivar o aprimoramento do espírito crítico, bem como a atuação profissional pautada na cidadania e na função social da educação superior.

Sendo assim, podemos evidenciar essa questão em nossas análises. Nota-se que as habilidades adquiridas pelos participantes durante o seu tempo no programa, contribuíram para o seu aprimoramento crítico e execução de atividades e ações no âmbito profissional. Em sua maioria, os ex-petianos atuam e desenvolvem atividades em grupos, fazendo valer, dessa forma, a filosofia petiana de manter boas relações interpessoais, primando por um trabalho de excelência. Como pode ser observado no Gráfico 5, 15 entrevistados (representando um percentual de 78,9\%), dos membros egressos que participaram da pesquisa, responderam positivamente no que se refere a obtenção de habilidades de análise crítica em seus ambientes de trabalho, enquanto que apenas três egressos foram indiferentes e um respondeu que as habilidades adquiridas no PET não ajudaram nas ações em seu ambiente de trabalho.

Gráfico 5 - Habilidades de análise crítica, adquiridas no PET Geografia, que ajudaram em ações no ambiente de trabalho

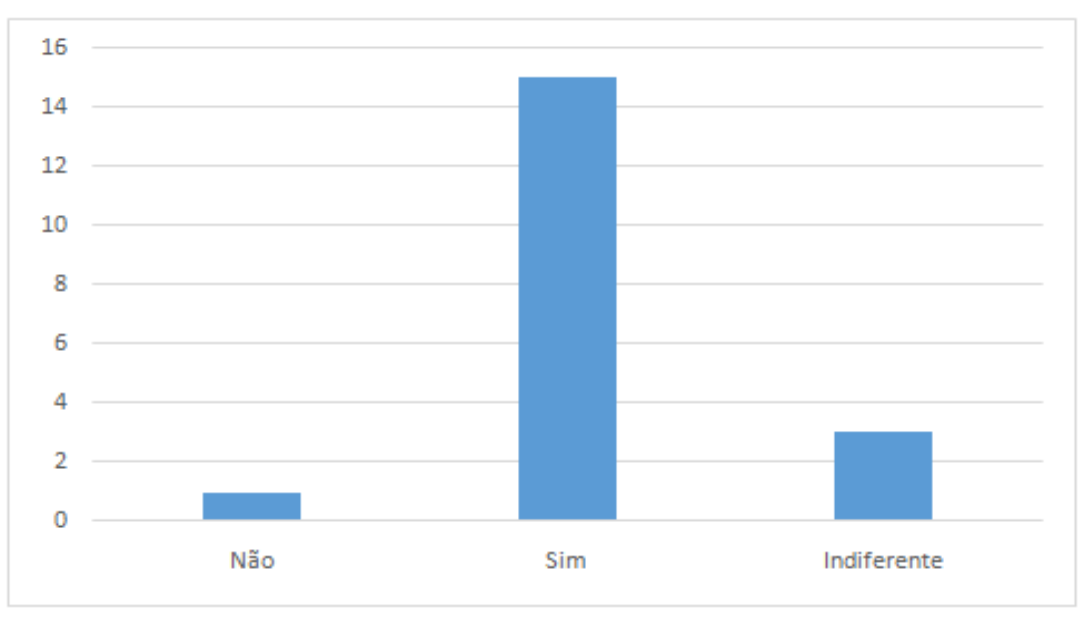

Fonte: Pesquisa própria / PET Geografia UFRN (2018). 
Entre os participantes da pesquisa, notam-se diferentes áreas as quais os egressos do PETGEO estão atuando. Estas variam entre a docência (no ensino superior e ensino básico), analistas (ambiental e de saneamento básico), técnico em geociências, geógrafo, assistente administrativo, estudantes e um caso de desemprego (Tabela 1).

Figura 1 - Profissões Exercidas Atualmente pelos Petianos Egressos

\begin{tabular}{|l|r|}
\hline \multicolumn{1}{|c|}{ Profissão exercida atualmente } & Quantidade \\
\hline Professor de Ensino Superior & 1 \\
\hline Professor de Ensino Básico & 8 \\
\hline Analista Ambiental & 1 \\
\hline Analista de Saneamento Básico & 1 \\
\hline Técnico em Geociências & 1 \\
\hline Geógrafo & 1 \\
\hline Agente Administrativa & 1 \\
\hline Estudante & 3 \\
\hline Graduanda em Geografia - Bacharelado & 1 \\
\hline Desempregado & 1 \\
\hline
\end{tabular}

Fonte: Pesquisa própria / PET Geografia UFRN (2018).

No grupo de participantes da pesquisa, ficou evidente que as pessoas que afirmaram não estar utilizando as habilidades que aprenderam no PET durante sua permanência, são as mesmas que desempenham uma atividade profissional distante da área ao qual se formaram. Todavia, em sua grande maioria, tanto os entrevistados que atuam na docência quanto em áreas técnicas da Geografia, afirmam carregar bagagens do programa até os dias atuais, e que estas os ajudam a realizar seus trabalhos no âmbito profissional. Diante do questionamento: Que ensinamentos/aprendizados foi levado do PET Geografia UFRN para a sua vida profissional?, obtivemos respostas que evidenciaram positivamente a contribuição do Programa no processo de formação. Foram relatados aspectos como: "Disciplina, trabalho em equipe e prática profissional", "O lidar com o ambiente de trabalho coletivo", "A importância das datas e organização com o planejamento ", além de "entender as necessidades do outro; trabalhando em equipe; e contribuindo para que o resultado da tarefa seja positivo".

As respostas perpassaram por um viés profissional, assim como também acadêmico e de crescimento individual. Todas os depoimentos dialogaram diretamente com a urbanidade e a essência do programa, no sentido de uma formação global e geração cidadãos críticos, autônomos e com excelência profissional. Dessa maneira, ao constatar de forma geral os resultados do levantamento quantitativo/qualitativo realizado por esta pesquisa, observa-se o desempenho que o PET Geografia UFRN conquistou ao longo de sua história no que compete 
à filosofia petiana implementada no Manual de Orientações Básicas (2006), assim como a grande ênfase e contribuição à formação profissional

\section{CONSIDERAÇÕES FINAIS}

O PET é um Programa do Estado brasileiro vinculado a universidade, tendo sido criado na década de 1970 com uma filosofia diferente da atual, e somente no ano de 2004 adquirindo uma versão mais completa e complexa relacionada a tríade de ensino, pesquisa e extensão. Esta tríade compõe o programa e oferece aos tutores e aos petianos a possibilidade de adquirir um bom desempenho social, acadêmico e profissional durante sua participação no Programa e posteriormente a ela. Dessa forma, constatou-se que as reuniões realizadas pelo grupo, os levantamentos bibliográficos, a pesquisa documental, o questionário via google docs, os gráficos, as tabelas e quadros realizados, foram necessários para se chegar aos resultados do presente artigo. Com isso, foi possível constatar que as exigências do programa para com os petianos, a exemplo do bom rendimento nas disciplinas, participação em eventos, participação ativa das atividades do PET, participação também em diferentes atividades, têm refletido diretamente na construção do conhecimento e no enriquecimento da vida acadêmica e profissional, além de contribuído para uma formação mais completa dos alunos de graduação em Geografia.

No que se refere a relação interpessoal dos membros que participaram do Programa, observou-se que grande parte desses firmaram ter um bom grau de satisfação. Quanto a relação dos petianos com o tutor observa-se que as respostas ficaram divididas em satisfeito, muito satisfeito e totalmente satisfeito, o qual sugere que, em geral, os bolsistas têm boa relação com o tutor do Programa, sendo que tal relação é essencial no desenvolvimento das atividades que são realizadas e no âmbito do crescimento do PET Geografia. Pode-se compreender ainda a partir dos questionários que, para a grande maioria dos ex-bolsistas, o PET contribui para além do processo da formação acadêmica, pois também atua na formação social e cidadã do indivíduo pela sua natureza coletiva e interdisciplinar. Constatou-se também que o PET Geografia contribui com o desempenho acadêmico do membro discente, pois 16 pessoas disseram que o programa os auxiliou no ganho de conhecimentos significativos.

É importante observar que as atividades, os trabalhos e a relação entre os membros do Programa é um importante mediador e incentivador na aquisição de habilidades de análise 
crítica, as quais auxiliam nas ações posteriores no ambiente de trabalho. Constatou-se que todas as contribuições do programa têm auxiliado na atuação profissional dos egressos do PET Geografia da UFRN, já que apenas um participante se encontra desempregado. Os demais egressos que responderam ao questionário estão atuando na área ou são estudantes da graduação ou de pós-graduação. Essa contribuição se confirma a partir das respostas dos petianos, afirmando que o Programa os ajudou em sua formação acadêmica, cidadã e profissional. 


\section{REFERÊNCIAS}

MANUAL DE ORIENTAÇÕES BÁSICAS: PROGRAMA DE EDUCAÇÃO TUTORIAL GEOGRAFIA (PET GEOGRAFIA UFRN), $2015 . \quad$ Disponível em:〈https://drive.google.com/file/d/0B3onGgCwL7zTdjNpYkl1TU5IV28/view>. Acesso em: 05 de nov. de 2018.

MARTINS, Iguatemy L. Educação Tutorial no ensino presencial: uma análise sobre o PET. PET-Programa de Educação Tutorial: estratégia para o desenvolvimento da graduação. Brasília: Ministério da Educação, 2007.

PET GEOGRAFIA UFRN. Atividades. Disponível em: <petgeografiaufrn.blogspot.com/p/atividades.html>. Acesso em: 05 de nov. de 2018.

XAVIER, Bruno T de L.; GOULART, Daniel Franco. Ensino, pesquisa e extensão consorciados: a fórmula do sucesso do Programa de Educação Tutorial. Portal MEC Secretaria de Educação Superior. Disponível em: $\langle$ http://portal.mec.gov.br/sesu/arquivos/pdf/PET/pet_texto_iii.pdf >. Acesso em: 13 de jun. de 2019. 